\title{
Effect of EGF on Bax, Bcl-2 and Fas expression in ulcerous disease and N87 cell line
}

\author{
Soylemez $\mathrm{F}^{1}$, Ay $\mathrm{OI}^{2}$, Ay E $\mathrm{E}^{2}$, Altintas $\mathrm{E}^{3}$, Turkseven $\mathrm{CH}^{4}$, Erdal $\mathrm{ME}^{2}$ \\ Department of Molecular Biology and Genetics, Avrasya University, Turkey. \\ cagatayhanturkseven1923@gmail.com
}

\begin{abstract}
BACKGROUND: To evaluate the effect of epithelial growth factor (EGF) in primary culture of ulcer patients and N87 cell line on expressions of apoptotic genes.

METHODS: Ulcer patients who attended Gastroenterology Clinic of Mersin University Medical Faculty were included in this study. Three different doses of EGF were applied to the primary culture of biopsy samples from ulcer patients and gastric cancer cell-line (ATCC-NCI-N87). The expression levels of Bax, Bcl-2 and Fas genes were measured with quantitative real-time PCR (qRT-PCR).

RESULTS: $\triangle \triangle C_{T}$ analysis with qRT-PCR revealed no significant change in gene expression of Bax, Bcl-2 or Fas within the ulcer, normal tissue and gastric cancer. No significant change was determined between Bax and $\mathrm{Bcl}-2$ gene expression levels and applied EGF doses when groups were compared for each EGF dose. On the other hand, when $50 \mathrm{ng} / \mathrm{\mu l}$ of EGF was administered, Fas mRNA expression level was significantly lower in the gastric cancer cell line compared to patients with ulcer and normal gastroduodenal tissue $(p<0.05)$.

CONCLUSION: In this study which was done with a restricted patient group, our results revealed that apoptosis induced by Fas expression in gastroduodenal suppressing carcinogenesis process plays an active role in gaining anti-apoptotic properties of cells (Tab. 4, Fig. 2, Ref. 27). Text in PDF www.elis.sk.

KEY WORDS: EGF, N87, primary culture of gastric epithelial cells, Fas, Bcl-2, Bax.
\end{abstract}

\section{Introduction}

The gastric mucosa is normally exposed to a wide range of aggressive factors and has developed efficient mechanisms to repair tissue injury. In the case of superficial damage, the regeneration of the epithelial surface is very rapid. In the case of deeper mucosal damage such as erosions and ulcers, both epithelial and connective tissue components, including sub-epithelial myofibroblast, smooth muscle cells, vessels, and nerves are destroyed and must be regenerated. Polypeptide growth factors such as epithelial growth factor (EGF) have received much attention in recent years because of their ability to regulate essential cell functions involved in tissue healing including cell proliferation, migration, differentiation, and secretion (1). EGF is synthesized by submandibular glands, Brunner's glands of the duodenum, and Paneth cells of the small intestine, but not in the normal gastric mucosa. The removal of

${ }^{1}$ Department of Molecular Biology and Genetics, Avrasya University, Turkey, ${ }^{2}$ Department of Medical Biology and Genetics, Mersin University, Turkey, ${ }^{3}$ Department of Gastroenterology, Mersin University, Turkey, and ${ }^{4}$ Department of Biophysics, Mersin University, Turkey

Address for correspondence: C.H. Turkseven, Mersin University Medicine of Faculty, Department of Biophysics, Mersin, Turkey. Phone: +90.324 .3610001$

Acknowledgement: This work was supported by The Scientific and Technological Research Council of Turkey (TUBITAK) with 108S108 project number, cofounded by the Scientific Research Projects Unit of Mersin University. submandibular glands in rats, which are the major source of EGF in the gastric fluid, may, although not sufficiently to cause spontaneous ulcer development, delay the healing of gastric ulcer, while oral administration of synthetic EGF can accelerate ulcer healing (2). In humans, salivary levels and gastric fluid concentrations of EGF are reduced during the active phase of peptic ulcer disease, but are restored to normal levels after ulcer healing is complete.

Apoptosis is an essential part of the cycle of cellular turnover in many tissues, including the gastrointestinal tract. Apoptosis has been reported to take place in all regions of the stomach, occurring predominantly in the upper part of the gastric glands and involving $2-3 \%$ of all epithelial cells (3). At the onset of gastric ulceration, the rate of apoptosis rapidly increases. A 3.9-fold increase in mucosal expression of caspase- 3 activity can be detected as early as 2 hours after experimental ulcer induction (4). Conceptually, apoptosis is an active and regulated process by which cells self-destruct. Deranged apoptosis has been implicated in carcinogenesis, autoimmune diseases, and various infectious diseases including Helicobacter pylori infection (5). The regulation of apoptosis is a complex process that includes the activation of various apoptosis-related proteins such as the BCL2-associated X protein (BAX), B-cell CLL/Lymphoma 2 (BCL-2), p53, TNF receptor super family, member 6 (FAS), Fas ligand (FASL) and Interleukin-1 $\beta$-related concerning enzyme (ICE) family (6). There are two pathways that lead to apoptosis: the positive induction by ligands binding to plasma membrane receptors, and negative induction by the loss of suppressor activity. One pathway involves 


\section{5-701}

apoptosis mediated by death receptors such as CD95 (Fas) and tumor necrosis factor receptors.

The Bcl-2 proteins are the best-studied family of proteins involved in the mechanism of apoptotic cell death. The first member of this family, Bcl-2, was discovered in human B-cell lymphomas at a chromosomal translocation $\mathrm{t}(14: 18)$ where it was thought to lead to malignant transformation because of its ability to prevent apoptotic cell death (7). Some members of the Bcl-2 family such as Bax promote apoptosis whereas other members such as Bcl2 and Bcl-xL inhibit this process. The susceptibility of a cell to apoptosis depends on the balance between apoptosis-promoting and apoptosis-suppressing factors (8).

Expression of genes related to apoptosis in both mRNA and protein levels have been studied in various types of cancer like gastric cancer, however, the effect of epidermal growth factor on gene expression has not been examined on ulcer tissues.

Apoptotic cell death is a highly regulated process, which plays a crucial role in many biological events. The regulation of apoptosis at several levels is essential to maintain the delicate balance between cellular survival and death signaling that is required to prevent disease. Apoptosis can be triggered by signals from within the cell or by extrinsic signals such as the growth factors. Several mechanisms have been implicated in the pathogenesis of stress ulcers, such as an increase in gastric acid and pepsin secretion, and decrease in gastric blood flow. EGF exhibits gastroprotective and ulcer-healing properties, presumably due to mitogenic and growth-promoting actions. It is also known that EGF family members in gastric cancer are elevated in expressions and suppressed apoptosis leading to carcinogenesis (9).

The aim of the present study is to analyze the effect of EGF in ulcer patients on expressions of genes related to apoptosis (Bax, Bcl-2, Fas), and show the similarities and/or differences, if any, among expression patterns in the cell line.

\section{Materials and methods}

\section{Primary culture of biopsy samples}

Twenty-six ulcer patients who attended Gastroenterology Clinic of Mersin University Medical Faculty were included in this study. All ulcer patients gave written informed consent, and the project was reviewed and accepted by the Ethics Committee of Mersin University, Turkey. Gastroduodenal biopsies were obtained from patients undergoing upper endoscopy. Biopsy samples were taken either from the body of the stomach, or its antrum. The
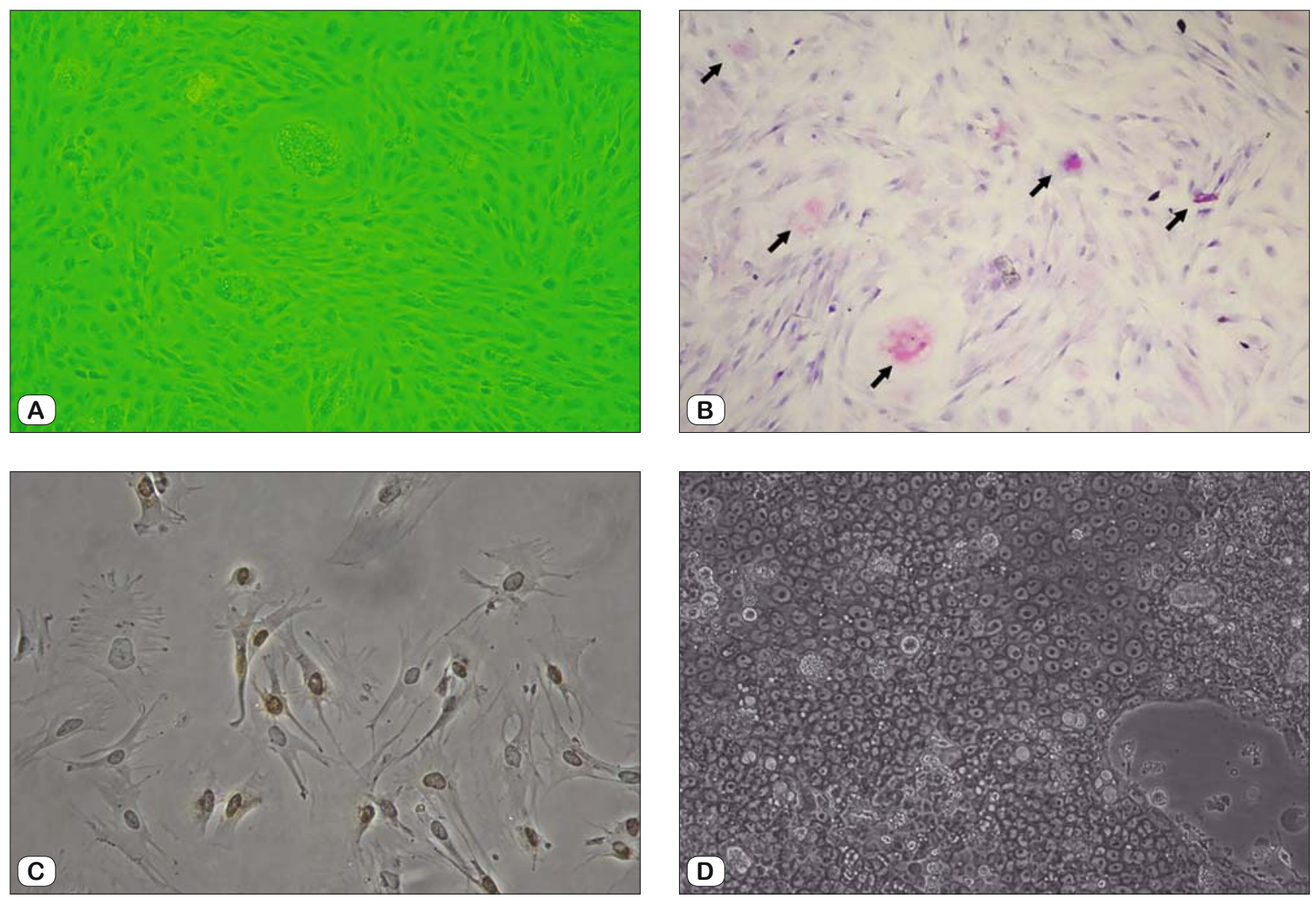

Fig. 1. A: Photograph of cultured stomach epithelium cells before PAS. B: Photograph of cultured stomach epithelium cells after PAS. PAS positive cells are characterized by the lilac staining which shows neutral mucin existence. (Nikon Eclipse, TS 100). C: Photograph of active DNA synthesis is determined in stomach epithelium cells after PCNA (Olympus BX50) (100X). D: The inverted microscope (Nikon Eclipse, TS 100) appearance of gastric epithelial cells reproduced from N87 cell line. 
Tab. 1. Primer and probe sequences used for qRT-PCR. *www.ncbi.nlm.nih.gov/gene.

\begin{tabular}{|c|c|c|}
\hline Gene Name & * mRNA Nucleotide Sequence No & Primer and Probe Sequences \\
\hline Bax & $N M \_138761.3$ & $\begin{array}{l}\text { F 5'- GGTTGTCGCCCTTTTCTACTTTG -3' } \\
\text { R 5'- CAGTTCCGGCACCTTGGT -3' } \\
\text { Pr 5'-FAM-CAGCAAACTGGTGCTCAAGGCCCT- BHQ-1-3' }\end{array}$ \\
\hline$B c l-2$ & $A Y 220759.1$ & $\begin{array}{l}\text { F 5'-GGATTGTGGCCTTCTTTGAGTT-3' } \\
\text { R 5'-TCCACAGGGCGATGTTGTC-3' } \\
\text { Pr 5'-FAM-TCAACCGGGAGATGTCGCCCC-BHQ-1-3' }\end{array}$ \\
\hline Fas & ВC012479.1 & $\begin{array}{l}\text { F 5'-CACTGTGACCCTTGCACCAA-3' } \\
\text { R 5'-AGTTAGATCTGGATCCTTCCTCTTTG-3' } \\
\text { Pr 5'-FAM- AATCATCAAGGAATGCACACTCACCAGCA- BHQ-1-3' }\end{array}$ \\
\hline$\beta$-actin & NM_001101.3 & 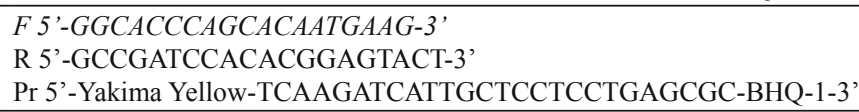 \\
\hline
\end{tabular}

F - Forward, R - Reverse, $\operatorname{Pr}-$ Probe

gastroduodenal biopsy samples were taken from grossly normal gastric mucosa. These endoscopic biopsy samples contained only mucosa (surface and deep glandular epithelium). The specimens were collected in Leibowitz's L-15 medium (Life Technologies) containing $1 \%$ penicillin/streptomycin (Life Technologies) for transport of tissue biopsy sample from hospital to our laboratory.

The primary culture was formed as described by Smooth DT from the ulcerous and control biopsy specimens (10). Biopsy specimens were enzymatically disintegrated into Leibowitz L-15 solution consisting of type II collagenase (Biochrom $0.05 \%$ and Dispase (120U). Then, within Ham's F12 medium (10\% fetal bovine serum, $1 \%$ penicillin-streptomycin, $1 \%$ AmphotericinB), primary culture was incubated into four different $35-\mathrm{mm}$ culture dishes. The culture was incubated at $37^{\circ} \mathrm{C}$ in an incubator with $5 \% \mathrm{CO}_{2}$.

\section{Characterization of gastroduodenal epithelial cells}

After maintaining the epithelial cells in the culture dishes, periodic acid shift (PAS) staining was carried out in order to characterize stomach epithelium cells and add neutral mucin into them. PAS colors the stomach epithelial cells secreting mucin into lilac, and the nuclei of the cells are seen as light blue. Cultured stomach photographs of epithelial cells were taken both before PAS (Fig. 1A) and after it. As a result of PAS, great quantities of PAS-positive cells were observed (Fig. 1B). To show a continuous division of epithelial cells and active DNA synthesis in the stomach, immunohistochemistry was done with proliferative cell nuclear antibody (PCNA) (Fig. 1C).

\section{EGF doses and application}

The medium in the culture dishes, which was determined to be confluent as a result of feedings at definite times and microscope observations, was removed and incomplete medium was added and kept in this way for 24 hours. After 24 hours, EGF (SigmaE9644) applications were performed to dishes at three different doses (0-control; 1 st dose: $20 \mathrm{ng} / \mu \mathrm{l}$; 2 nd dose: $50 \mathrm{ng} / \mu \mathrm{l}$; $3 \mathrm{rd}$ dose: $100 \mathrm{ng} / \mu \mathrm{l})$. Twenty-four hours following the EGF application, cell count was conducted by removing the cells (Biochrome-Trypsin/ EDTA $\left./ 1.2 \times 10^{6} \mathrm{ml}\right)$.

\section{Cell line procedure}

The gastric carcinoma cell line named N87 was also treated with EGF (ATCC-NCI-N87). The N87 cells resuspended with complete medium (Biochrom-RPMI-1640, $10 \%$ FBS, $1 \%$ penicillin-streptomycin, $1 \%$ amphotercin-B) and dispensed into culture dishes. The culture was incubated at $37{ }^{\circ} \mathrm{C}$ in an incubator with $5 \% \mathrm{CO}_{2}$. Flasks were followed regularly with an inverted microscope (Olymphus CK40, 40X). The confluent flasks were passaged in a dilution ratio of $1: 3$. The cells in the flasks were photographed (Fig. 1D). EGF application was similarly held with primary culture.

\section{RNA extraction}

The extraction of total RNA from primary cell cultures and cell line was carried out with acid guanidinium thiocyanate-phenol-chloroform (AGPC) method (11). Following precipitation, RNA samples were dissolved in $50 \mu \mathrm{L}$ DEPC water and stored at $-80{ }^{\circ} \mathrm{C}$ until analysis.

\section{Reverse transcriptase PCR (RT-PCR) reactions}

Reverse transcriptase reactions contained $5 \mu \mathrm{g}$ of extracted total RNA, $50 \mathrm{nM}$ oligo dT primary, $1 \times$ RT buffer, $0.25 \mathrm{mM}$ each of dNTPs, 50 units of modified M-MuLV reverse transcriptase (Thermo Scientific, Vilnius, Lithuania), 25 units of RiboLock RNase inhibitor (Thermo Scientific, Vilnius, Lithuania) and nuclease-free water at a total reaction volume of $15 \mu$. The reaction was performed with an automated Thermal Cycler (Techne Flexigene, Cambridge, UK).

RT-PCR reactions were carried out under conditions of being kept at $37^{\circ} \mathrm{C}$ for 60 minutes, at $95{ }^{\circ} \mathrm{C}$ for 5 minutes, and at $4{ }^{\circ} \mathrm{C}$.

Detection of Bax, Bcl-2 and Fas expression with $\Delta \triangle C T$ method of $q R T-P C R$

The qRT-PCR was performed with ABI Prism 7500 Real-Time PCR System and SDS 2.0.6 software for 7500 Real Time PCR product (Applied Biosystems, Foster City, CA, USA). Having taken into consideration information on the Bax, Bcl-2, Fas and $\beta$-actin cDNA sequences, two pairs of gene-specific primaries were designed by Primary Express Program 3.0 (Applied Biosystems). 
695-701

Primaries and probes were created from NM_138761.3 Homo sapiens BCL2-associated X protein (BAX), transcript variant alpha, mRNA of Bax (12), AY220759.1 Homo sapiens B-cell CLL/ Lymphoma 2 (BCL2) mRNA of Bcl-2 (13), BC012479.1 Homo sapiens TNF receptor super family, member 6 (FAS) mRNA of Fas (14) and NM_001101.3 Homo sapiens actin, beta (ACTB), mRNA of $\beta$-actin (Tab. 1) (15). The sequences of primaries and probes were synthesized by Metabion International AG, D-82152 Martinsried/Deutschland.

Bax, Bcl-2, Fas and $\beta$-actin expressions were analyzed using the comparative $\mathrm{C}_{\mathrm{T}}\left(\Delta \Delta \mathrm{C}_{\mathrm{T}}\right)$ method (16-18). The $25 \mu 1$ PCR reaction included $2.5 \mu \mathrm{l}$ of cDNA, $12.5 \mu 1$ TaqMan Gene Expression Master Mix (Applied Biosystems), $900 \mathrm{nmol}$ of gene-specific primaries and $200 \mathrm{nmol}$ of specific labeling probes. The cycling conditions were as follows: one cycle of pre-incubation at $50{ }^{\circ} \mathrm{C}$ for 2 minutes, denaturation at $95^{\circ} \mathrm{C}$ for 10 minutes, followed by 40 cycles of $95^{\circ} \mathrm{C}$ for 15 seconds, $60^{\circ} \mathrm{C}$ for 1 minute. $\beta$-actin was used as an endogenous control gene for PCR normalization concerning the amount of RNA added to the reverse transcription reactions. Moreover, the standard RNA (TaqMan Control-Human RNA) was used for $\mathrm{C}_{\mathrm{T}}$ analysis as internal control. Each real-time PCR reaction was performed in duplicate in order to assess data reproducibility.

\section{Statistical analysis}

The minimum sampling size was calculated using the MedCalc Free Trial statistical software package to be significant of differ- ences between the mean values of the groups (alpha $=0.05$ and power of test $=0.80$ ). Expression data were assessed by KruskalWallis test followed by Dunn's test. All statistical analyses were performed using the SPSS software 21 and Statica software 8.0. The value of $p<0.05$ value was defined as being statistically significant.

\section{Results}

In this study, the comparative $\mathrm{C}_{\mathrm{T}}$ quantification $\left(\Delta \Delta \mathrm{C}_{\mathrm{T}}\right.$ method) of qRT-PCR for comparing the changes in gene expression of Bax, Bcl-2 and Fas was applied following primary culture of gastroduodenal epithelial cells from ulcer patients, and gastric cancer cell line (N87). Relative quantification was performed using $\beta$-actin as endogenous control gene. $\beta$-actin exhibited the less variability among the samples as determined by the analysis of the standard deviation of the threshold cycles $\left(\mathrm{C}_{\mathrm{T}}\right)$ values (Fig. 2).

Expression of Fas in primary culture of ucer and normal gastric cells and N87 cell line

The expression level of Fas mRNA did not have a significant difference in the ulcer, gastric cancer and normal gastric tissues. However, a significant difference was identified in Fas gene expression only in tissues to which $50 \mathrm{ng} / \mathrm{ml}$ EGF was applied. Moreover, Fas gene expression level was significantly lower in gastric cancer cell line than in duodenal ulcer and normal gastric tissue
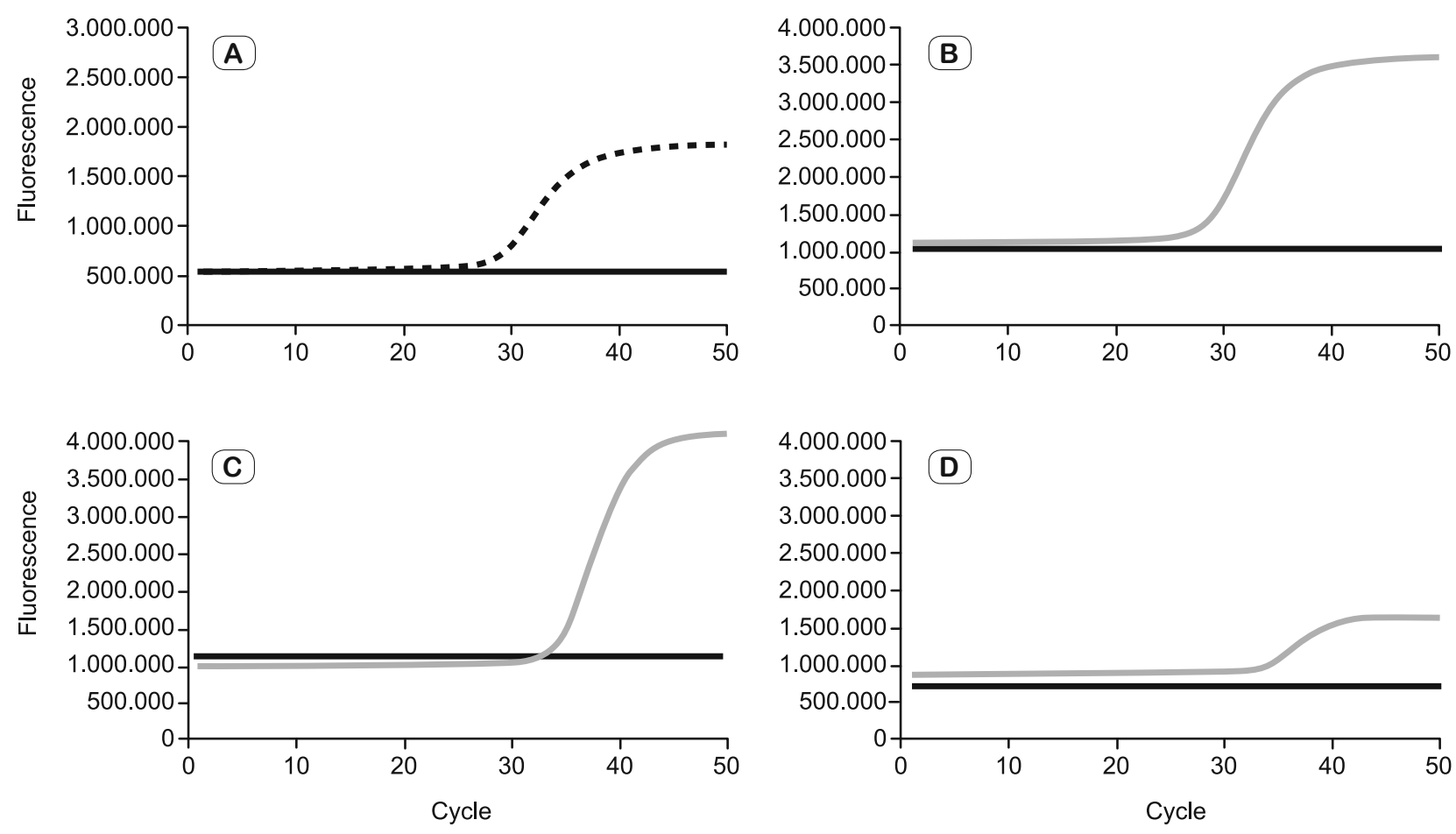

$$
\text { ROX \#VIC }=\text { FAM }
$$

Fig. 2. Amplification curves of $\beta$-actin labeling Yakima A - Yellow, B - Bax, C - Fas, D - Bcl-2 labeling FAM in the qRT-PCR. 
Tab. 2. Relationship between Fas mRNA expression levels and EGF doses in the groups.

\begin{tabular}{|c|c|c|c|c|c|}
\hline Group & EGF & $\begin{array}{c}\text { Expression } \\
\text { Value }\left(2^{-\Delta \Delta C T}\right) \\
\end{array}$ & $25 \%$ & $75 \%$ & $\mathrm{p}_{\mathrm{a}}$ \\
\hline \multirow{4}{*}{$\mathrm{C}$} & 0 & 0.75 & 0.10 & 1.00 & \multirow{4}{*}{0.839} \\
\hline & 1 & 0.49 & 0.09 & 1.00 & \\
\hline & 2 & 0.82 & 0.24 & 1.00 & \\
\hline & 3 & 0.22 & 0.12 & 1.00 & \\
\hline \multirow{4}{*}{ GU } & 0 & 0.39 & 0.11 & 1.00 & \multirow{4}{*}{0.291} \\
\hline & 1 & 1.00 & 0.61 & 1.00 & \\
\hline & 2 & 0.62 & 0.03 & 1.00 & \\
\hline & 3 & 0.51 & 0.38 & 1.00 & \\
\hline \multirow{4}{*}{ DU } & 0 & 1.00 & 0.07 & 1.00 & \multirow{4}{*}{0.918} \\
\hline & 1 & 1.00 & 0.12 & 1.00 & \\
\hline & 2 & 1.00 & 0.07 & 1.00 & \\
\hline & 3 & 1.00 & 0.10 & 1.00 & \\
\hline \multirow{4}{*}{ N87 } & 0 & 0.04 & 0.02 & 1.00 & \multirow{4}{*}{0.244} \\
\hline & 1 & 1.00 & 0.02 & 1.14 & \\
\hline & 2 & $0.01^{\text {*\# }}$ & 0.01 & 0.05 & \\
\hline & 3 & 1.00 & 0.40 & 1.05 & \\
\hline \multirow{4}{*}{$\mathrm{P}_{\mathrm{b}}$} & 0 & 0.671 & & & \\
\hline & 1 & 0.557 & & & \\
\hline & 2 & 0.006 & & & \\
\hline & 3 & 0.622 & & & \\
\hline
\end{tabular}

C - Control, GU - Gastric ulcer, DU - Duodenal ulcer, N87 - Gastric cancer cell line $\mathrm{P}_{\mathrm{a}}$ - The comparison between EGF doses of expression values for each group; $\mathrm{P}_{\mathrm{b}}$ - The comparison between the groups of expression values for each EGF dose

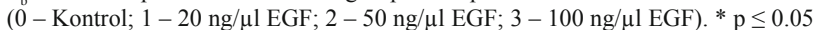
when compared to control ${ }^{\#} \mathrm{p} \leq 0.05$ when compared to DU

samples as a result of the application of $50 \mathrm{ng} / \mathrm{ml} \mathrm{EGF}$ in gastric cancer $(\mathrm{p}<0.05)$ (Tab. 2).

Expression of Bax in primary culture of ulcer and normal gastric cells and N87 cell line

The results of the study revealed that there were no significant differences in Bax mRNA expression levels in the primary culture, normal gastric cells, or N87 cell lines from ulcer patients. Also, the expression level of Bax mRNA and applied EGF doses were not significantly different when groups were compared for each EGF dose (Tab. 3).

Expression of Bcl-2 in primary culture of ulcer, normal gastric cells and N87 cell line

The expression level of Bcl-2 mRNA did not have a significant difference in the ulcer, gastric cancer and normal gastric tissues. Significant differences were not determined between Bcl-2 gene expression levels and applied EGF doses when groups were compared for each EGF dose (Tab. 4).

\section{Discussion}

Peptic ulcer is a distinct breach in the mucosal lining of the stomach (gastric ulcer) or in the first part of the small intestine (duodenal ulcer) as a result of caustic effects of acid and pepsin in the lumen.

It is the most common ulcer of the gastrointestinal tract. Various polypeptide growth factors were shown to have an important role in mucosal cell proliferation and regulation of its differen-
Tab. 3. Relationship between Bax mRNA expression levels and EGF doses in the groups.

\begin{tabular}{|c|c|c|c|c|c|}
\hline Group & EGF & $\begin{array}{c}\text { Expression } \\
\text { Value }\left(2^{-\Delta \Delta C T}\right) \\
\end{array}$ & $25 \%$ & $75 \%$ & $\mathrm{p}_{\mathrm{a}}$ \\
\hline \multirow{4}{*}{ C } & 0 & 1.00 & 0.53 & 7.92 & \multirow{4}{*}{0.64} \\
\hline & 1 & 1.85 & 0.77 & 10.77 & \\
\hline & 2 & 7.31 & 1.97 & 13.43 & \\
\hline & 3 & 1.73 & 0.67 & 9.38 & \\
\hline \multirow{4}{*}{ GU } & 0 & 6.79 & 0.47 & 25.20 & \multirow{4}{*}{0.673} \\
\hline & 1 & 1.91 & 0.07 & 13.79 & \\
\hline & 2 & 1.00 & 0.86 & 3.16 & \\
\hline & 3 & 1.83 & 0.10 & 4.18 & \\
\hline \multirow{4}{*}{ DU } & 0 & 0.51 & 0.09 & 1.24 & \multirow{4}{*}{0.412} \\
\hline & 1 & 1.00 & 0.12 & 3.16 & \\
\hline & 2 & 1.02 & 0.08 & 6.66 & \\
\hline & 3 & 0.33 & 0.14 & 1.08 & \\
\hline \multirow{4}{*}{ N87 } & 0 & 1.78 & 0.71 & 5.71 & \multirow{4}{*}{0.402} \\
\hline & 1 & 1.20 & 0.30 & 1.52 & \\
\hline & 2 & 0.79 & 0.38 & 1.11 & \\
\hline & 3 & 0.91 & 0.36 & 7.76 & \\
\hline \multirow{4}{*}{$P_{b}$} & 0 & 0.051 & & & \\
\hline & 1 & 0.630 & & & \\
\hline & 2 & 0.199 & & & \\
\hline & 3 & 0.115 & & & \\
\hline
\end{tabular}

C - Control, GU - Gastric ulcer, DU - Duodenal ulcer, N87 - Gastric cancer cell line $\mathrm{P}_{\mathrm{a}}$ - The comparison between EGF doses of expression values for each group; $\mathrm{P}_{\mathrm{b}}$ - The comparison between the groups of expression values for each EGF dose (0

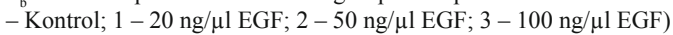

Tab. 4. Relationship between Bcl-2 mRNA expression levels and EGF doses in the groups.

\begin{tabular}{|c|c|c|c|c|c|}
\hline Group & EGF & $\begin{array}{c}\text { Expression } \\
\text { Value }\left(2^{-\Delta \Delta C \mathrm{CT}}\right)\end{array}$ & $25 \%$ & $75 \%$ & $\mathrm{p}_{\mathrm{a}}$ \\
\hline \multirow{4}{*}{$\mathrm{C}$} & 0 & 89.99 & 57.71 & 113 & \multirow{4}{*}{0.722} \\
\hline & 1 & 106.94 & 23.20 & 156 & \\
\hline & 2 & 106.70 & 47.12 & 148.8 & \\
\hline & 3 & 113.38 & 50.35 & 187.1 & \\
\hline \multirow{4}{*}{ GU } & 0 & 28.05 & 0.82 & 82.56 & \multirow{4}{*}{0.253} \\
\hline & 1 & 97.77 & 7.07 & 137.2 & \\
\hline & 2 & 98.36 & 30.37 & 147.8 & \\
\hline & 3 & 133.99 & 40.55 & 156.4 & \\
\hline \multirow{4}{*}{ DU } & 0 & 17.28 & 12.54 & 126.3 & \multirow{4}{*}{0.107} \\
\hline & 1 & 117.46 & 79.40 & 147.10 & \\
\hline & 2 & 98.53 & 36.60 & 159.5 & \\
\hline & 3 & 130.68 & 74.03 & 160.09 & \\
\hline \multirow{4}{*}{ N87 } & 0 & 47.83 & 37.10 & 210.5 & \multirow{4}{*}{0.169} \\
\hline & 1 & 80.44 & 52.40 & 283.6 & \\
\hline & 2 & 39.39 & 25.65 & 81.18 & \\
\hline & 3 & 81.57 & 70.92 & 170.6 & \\
\hline \multirow{4}{*}{$P_{b}$} & 0 & 0.482 & & & \\
\hline & 1 & 0.798 & & & \\
\hline & 2 & 0.331 & & & \\
\hline & 3 & 0.532 & & & \\
\hline
\end{tabular}

tiation during the healing process of gastric and duodenal ulcers. One of these growths factors, namely EGF, was determined in the human normal gastric mucosa (19). EGF was thought to show activities in gut lumen of EGF as a gastrointestinal growth factor (20). 
The expression of genes related to apoptosis has been studied in many cancer types including gastric cancer. However, there is no published study about the effect of EGF on expressions of these genes in gastric or duodenal ulcers. It has been stated that ulceration in the gastrointestinal system induces EGF immune reactivity within the boundaries of an ulcer (21). These studies show that the ulcerative process in the human gastrointestinal system induces the development of new cells from stem cells secreting EGF. On the other hand, it has been observed that there has been no increase in the process of gastric damage in EGF expression while raising TGF- $\alpha$ mRNA and protein expression in the rat gastric mucosa where acute damage is caused with hydrochloride and taurocholate (22). These contradictions about EGF expression in the previous studies may be brought about by current antibody depending on the immunohistochemical method that is used, tissue preparations or differences in the present phase of evaluated gastric ulcer.

It has been demonstrated that apoptosis is in every part of the stomach and it is induced after acute mucosal damage and during the period of gastric ulcer healing. It was found that Bax and p53 expressions increased in gastric ulcer, and $\mathrm{Bcl}-2$ expression was also similar to the controls. In this study, the expression levels of Bax, Fas and Bcl-2 genes in gastric ulcer, duodenal ulcer and gastric cancer were evaluated in EGF presence. The expression level of Bax, Bcl-2 and Fas mRNA was found to be similar in the ulcer, normal gastric cell and N87 cell line.

No relationship was found between Bax and Bcl-2 expression levels and EGF doses that were performed on primary cell cultures from ulcer patients and gastric cancer cell line. However, a significant difference was identified in Fas gene expression only in tissues to which $50 \mathrm{ng} / \mu \mathrm{l} \mathrm{EGF}$ was applied. Also, Fas gene expression levels were significantly lower in the gastric cancer cell line than in the patients with duodenal ulcer and normal gastric tissue samples as a result of the application of $50 \mathrm{ng} / \mu \mathrm{l} \mathrm{EGF}$ in gastric cancer cell line $(\mathrm{p}<0.05)$.

Gastric cancer is one of the most common malignant tumors in the world. Currently, no effective treatment modalities are available for its metastasis and recurrence. Epidemiological studies have implicated that colonization of the stomach by Helicobacter pylori is a risk factor for the development of gastric diseases including gastric cancer (23). Abnormal Fas expressions in gastric carcinoma are involved in carcinogenesis and metastasis of gastric cancer. Fas, a cell-surface receptor, activates the apoptosis signal pathway by binding to its ligand, FasL, resulting in cancer cell apoptosis.

By investigating the role of Fas expression in the carcinogenesis and metastasis of gastric carcinoma, several investigators have found that Fas expression in gastric carcinoma is decreased. It is shown that Fas expression level was lower in gastric carcinoma tissue samples than in normal gastric mucosa tissue samples (24). It was suggested that the expression of Fas protein was downregulated with the increase in gastric carcinoma volume and malignancy degree (25).

The Fas protein encoded by Fas gene is a member of the TNFreceptor superfamily. This receptor contains a death domain. It has been shown to play a central role in the physiological regulation of programmed cell death, and has been implicated in the pathogenesis of various malignancies and diseases of the immune system. The interaction of this receptor with its ligand allows the formation of a death-inducing signaling complex that includes Fas-associated death domain protein (FADD), caspase 8, and caspase 10 . The autoproteolytic processing of the caspases triggers a downstream caspase cascade, and leads to apoptosis. Recently, Fas has also been shown to promote tumor growth, since during tumor progression, it is frequently downregulated. Cancer cells in general, regardless of their Fas apoptosis sensitivity, depend on the constitutive activity of Fas.

On the other hand, Helicobacter pylori infection is now accepted to be linked to severe gastritis-associated diseases, including peptic ulcer and gastric cancer. The infection remains latent in the majority of infected patients, and only a minority of individuals with $H$. pylori infection ever develops the disease (26). It has been reported that gastric cancer develops in approximately $3 \%$ of $H$. pylori-infected patients during the observational period of 10 years, compared to none of the uninfected patients (27).

EGF is known to play a role in regulating mucosal cell proliferation in the process of gastric ulcer healing. It is shown that increasing cell proliferation in the gastric mucosa infected with Helicobacter pylori may correlate with the upregulation of EGF. In this study, since $H$. pylori results from patients could not be obtained, the ability to comment on the results of this topic are limited. As a result of this research, expression of Fas mRNA was found to be lower than that of ulcers. Several investigators have also found that Fas expression in gastric carcinoma has decreased. In the case of ulcer patients, each gene has its own proliferative effect in proportion to apoptotic genes and EGF concentrations, but there is no statistical difference between the expression values for each EGF concentration.

Although the incidence and mortality rate have been decreasing in recent decades, gastric cancer is still one of the most common malignancies in the world. Although $H$. pylori may have no carcinogenesis-promoting effect itself, infection causes inflammation of the gastric mucosa and chronic infection causes mucosal atrophy resulting in intestinal metaplasia. Apoptosis and oxidative stress are closely interrelated and may play a determinant role in the evolution of ulcer to gastric carcinogenesis. Further progress in epidemiologic research is needed to resolve this issue. In this study, decreased expression of Fas mRNA was observed in gastric cancer while elevated Fas mRNA expression levels were determined in duodenal ulcer compared to healthy gastric epithelial cells with EGF application. The process of gastric carcinogenesis may have a relationship with abnormal expression of Fas mRNA depending on EGF in ulcer patients.

In the case of ulcer patients, each gene has its own proliferative effect in proportion to apoptotic genes and EGF concentrations, but there is no statistical difference between the expression values for each EGF concentration.

\section{Conclusion}

In conclusion, the elevation of Fas expression in ulcer compared to gastric cancer suggests that the effect of EGF on altering 
the balance between pro-apoptotic and anti-apoptotic gene expressions in the site of injury is a possible mechanism to maintain the integrity of gastric mucosa.

\section{References}

1. Milani S, Calabro A. Role of Growth Factors and Their Receptors in Gastric Ulcer Healing. Microsc Res Tech 2001; 53: 360-371.

2. Abe S, Sasano H, Katoh K, Ohara S, Arikawa T, Noguchi T, Asaki S, Yasui W, Tahara E, Nagura H, Toyota T. Immunohistochemical Studies on EGF Family Growth Factors in Normal and Ulcerated Human Gastric Mucosa. Dig Dis and Sci 1997; 42: 1199-1209.

3. Szabó I, Tarnawski AS. Apoptosis in the gastric mucosa: molecular mechanisms, basic and clinical implications. J Physiol Pharmacol 2000; 51: $3-15$.

4. Von HA, Rudi J. Role of Apoptosis in Gastric Epithelial Turnover. Microscopy Res and Tech 2000; 48: 303-311.

5. Moss SF, Calam J, Agarwal B, Wang S, Holt PR. Induction of gastric epithelial apoptosis by Helicobacter pylori. Gut 1996; 38: 498-501.

6. Chao DT, Korsmeyer SJ. Bcl-2 Family: Regulators of Cell Death. Annu Rev Immunol 1998; 16: 395-419.

7. Xiao G, Fang H, Xing C, Xu W. Structure, function and inhibition of Bcl-2 family proteins: a new target for anti-tumor agents. Med Chem 2009; 9: 1596-1604.

8. Brumatti G, Salmanidis M, Ekert PG. Crossing paths: interactions between the cell death machinery, growth factor survival signals. Cell Mol Life Sci 2010; 67: 18-29.

9. Nielsen TO, Friis-Hansen L, Poulsen SS, Federspiel B, Sorensen BS. Expression of the EGF Family in Gastric Cancer: Downregulation of HER4 and Its Activating Ligand NRG4. Plos one 2014; 9 (4): e94606.

10. Smoot DT, Sewchand J, Young K, Desbordes BC, Allen CR, Naab T. Method for establishing primary cultures of human gastric epithelial cells. Methods in Cell Sci 2000; 22: 133-136.

11. Chomczynski P, Sacchi N. Single-step method of RNA isolation by acid guanidinium thiocyanate-phenol-chloroform extraction. Anal Biochem 1987; 162: 156-159.

12. http://www.ncbi.nlm.nih.gov/nuccore/NM_138761 accessed NM_138761.

13. http://www.ncbi.nlm.nih.gov/nuccore/28144172 accessed AY220759.
14. http://www.ncbi.nlm.nih.gov/nuccore/BC012479.1 accessed BC012479.

15. https://www.ncbi.nIm.nih.gov/nuccore/NM_001101.3 accessed NM_001101.

16. Livak KJ, Schmittgen TD. Analysis of Relative Gene Expression Data Using Real-Time Quantitative PCR and the 2- $\Delta \Delta C T$ Method. Methods 2001; 25: 402-408.

17. Schmittgen TD, Livak KJ. Analyzing real-time PCR data by the comparative CT method. Nature Protoc 2008; 3: 1101-1108.

18. Schefe JH, Lehmann KE, Buschmann IR, Unger T, Funke-Kaiser H. Quantitative real-time RT-PCR data analysis: current concepts and the novel "gene expression's CT difference" Formula. J Mol Med 2006; 84: 901-910.

19. Wong BC, Wang WP, So WH, Shin VY, Wong WM, Fung FM, Liu ES, Hiu WM, Lam SK, Cho CH. Epidermal growth factor and its receptor in chronic active gastritis and gastroduodenal ulcer before and after Helicobacter pylori eradication. Aliment Pharmacol Ther 2001; 15: 1459-1465.

20. Playford RJ, Wright NA. Why is epidermal growth factor present in the gut lumen? Gut 1996; 38: 303.

21. Wright NA, Pike C, Elia G. Induction of a novel epidermal growth factor-secreting cell lineage by mucosal ulceration in human gastrointestinal stem cells. Nature 1990; 343: 82-85.

22. Polk WH, Dempsey PJ, Russell WE, Brown PI, Beauchamp RD, Barnard JA, Coffey Jr RJ. Increased production of transforming growth factor a following acute gastric injury. Gastroenterology 1992; 102: 14671474.

23. Nomura AM, Perez PGI, Lee J, Stemmermann G, Blaser MJ. Relation between Helicobacter pylori cagA status and risk of pep $\neg$ tic ulcer disease. Am J Epidemiol 2002; 155: 1054-1059.

24. Li Q, Peng J, Li XH, Liang QC, Zhang GY. Clinical significance of Fas and FasL protein expression in gastric carcinoma and local lymph node tissues. World J Gastroenterol 2010; 16: 1274-1278.

25. Suerbaum S, Michetti P. Helicobacter pylori infection. N Engl J Med 2002; 347: 1175-1186.

26. Kusters JG, Van VAH, Kuipers EJ. Pathogenesis of Helicobacter pylori infection. Clin Microbiol Rev 2006; 19: 449-490.

27. Uemura N, Okamoto S, Yamamoto S, Matsumura N, Yamaguchi S, Yamakido M, Taniyama K, Sasaki N, Schlemper RJ. Helicobacter pylori infection and the development of gastric cancer. N Engl J Med 2001; 345: 784-789. 